\title{
Toward a European Network of Positron Laboratories
}

\author{
Grzegorz P. Karwasz, \\ Roberto S. Brusa, \\ Werner Egger, \\ Olga V. Ogorodnikova
}

\begin{abstract}
$\overline{\text { Abstract. Some applications of controlled-energy positron beams in material studies are discussed. In porous }}$ organic polysilicates, measurements of $3 \gamma$ annihilation by Doppler broadening (DB) method at the Trento University allowed to trace pore closing and filling by water vapor. In silicon coimplanted by $\mathrm{He}^{+}$and $\mathrm{H}^{+}, \mathrm{DB}_{\text {data }}$ combined with positron lifetime measurements at the München pulsed positron beam allowed to explain Si blistering. Presently measured samples of $\mathrm{W}$ for applications in thermonuclear reactors, irradiated by $\mathrm{W}^{+}$and electrons, show vast changes of positron lifetimes, indicating complex dynamics of defects.
\end{abstract}

Key words: positron beams • material science • thermonuclear reaction

\section{G. P. Karwasz ${ }^{凶}$}

Institute of Physics, Faculty of Physics, Astronomy

and Applied Informatics,

Nicolaus Copernicus University in Torú,

5/7 Grudziądzka Str., 87-100 Toruń, Poland,

E-mail: karwasz@fizyka.umk.pl

\section{R. S. Brusa}

Physics Department,

University of Trento and TIFPA-INFN,

38123 Povo (TN), via Sommarive 14, Italy

\section{W. Egger}

Universität der Bundeswehr München,

Werner-Heisenberg-Weg 39, 85577 Neubiberg, Germany

O. V. Ogorodnikova

National Research Nuclear University "MEPHI",

Kashirskoe sh. 31, Moscow, Russia

Received: 4 August 2015

Accepted: 21 August 2015

\section{Positron defectoscopy}

Positron annihilation is one of the few really nondestructive techniques in material science, giving unique information on types and concentrations of defects, even at a single parts per million (ppm) level, see, for example, [1]. Applications of positron annihilation techniques span from semiconductors $[2,3]$ and metals [4] to polymers [5] and porous media [6]. In each case, answers given by positron methods are unique and complementary to other techniques.

Two most common techniques, the analysis of Doppler broadening (DB) of the 511-keV annihilation line and the positron lifetime measurements, are to some extent complementary. The broadening brings information on momenta of electrons that positrons annihilate with. The main contribution to the annihilation comes from valence electrons, that is, possessing a few electron-volts energy. In the relativistic transformation, these energies translate to broadening of a few kiloelectron-volts, i.e. similar to the intrinsic resolution of gamma detectors used in experiments. Therefore, the information on relative contributions from valence and core (i.e., from defect sites) electrons is not straightforward. Somewhat phenomenological line-broadening parameters (central area S parameter, $\mathrm{W}$ lateral area, $\mathrm{V} 3 \gamma$ annihilation) are used, and some normalization is needed to make comparison between different experiments and theories. Evaluation of DB requires not only information of the overlap between a positron and electrons in the material but also a detailed 
knowledge of electronic momenta of electrons that positrons annihilate with [7].

Theories are quite successful in predicting positron lifetime, especially in non-defected (and low-Z) materials. The experiment is not easy, again. In pure metals, positron lifetimes are in the 100-200 ps range, see, for example, [8]. The fastest techniques show intrinsic resolutions not better than 160-180 ps, see, for example, [9]. In order to extract components of lifetime spectra that are characteristic for a given type of defect, numerical deconvolution procedures should be applied and results are subject to careful validations, see, for example, [10]. Precise measurements allow to distinguish closely positioned lifetime components, such as 221 ps in pure silicon and 250 ps in oxygen (or arsenic) decorated vacancies in $\mathrm{Si}[11,12]$.

\section{Positron beams}

In order to obtain a depth-resolved defectoscopy, the energy of injected positrons should be controlled, i.e. positrons should form a beam [13-15]. Particularly difficult is constructing beams for lifetime measurements, as ultra-rapid bunching is needed [16, 17] .

In spite of numerous attempts, few positron beams are technologically operative. Several reasons lay behind, the principal being high-operative costs of positron sources. The most frequently used source is ${ }^{22} \mathrm{Na}$ isotope, uniquely from iThemba LABS, South Africa. Difficulties in preparing strong radioactive sources induced alternative ways of producing positrons. München lifetime apparatus [18] uses a neutron flux from Garching nuclear reactor. High-energy gamma produced in neutron capture in $\mathrm{Cd}$ are subsequently used for the production of $\mathrm{e}^{+} \mathrm{e}^{-}$ pairs production in the Bremsstrahlung process in a $\mathrm{Pt}$ foil. Combined DB and lifetime measurements at Japanese positron facility in Tsukuba use an intense positron beam produced by an electron linear accelerator and a brightness enhancement method [19].

The mean implantation depth is related to the positron energy and target density through the relation

$$
<z>=40 E^{1.6} / \rho
$$

where $z$ is given in $\mathrm{nm}, E$ in $\mathrm{keV}$, and $\rho$ in $\mathrm{g} / \mathrm{cm}^{3}$.

The implantation profile is expressed by a derivate of Gaussian function. Owing to this profile (and the diffusion length of thermalized positrons), the depth resolution worsens with the implantation depth. However, positrons remain particularly sensitive to any discontinuities, impurities, interior electrical fields, or even mechanical stress inside studied structures [20].

\section{Case study I - porous materials}

Porous materials are used as molecular sieves, as low- $\varepsilon$ dielectrics, and recently, as possible source of positronium for antigravity experiments [21]. In empty (i.e., air filled) cavities, the injected positron can attach an electron and form a free positronium. The ortho-positronium, annihilating into three gamma quanta and with lifetime of $142 \mathrm{~ns}$ is formed in the statistical weight $3: 1$ as compared to para-positronium (annihilating into two $511 \mathrm{keV}$ quanta and with 125 ps lifetime). In condensed matter, because of electron contact densities, the lifetime of $o$-Ps is shorter than that in a free space. The intensity of a long-lifetime (in the range of nanosecond) component is an indication of the presence of free volumes in the material, and the value of this lifetime is related to the cavity volume and shape [22, 23].

Large cavities (as deduced from positron lifetimes in tens of nanosecond range [24]) can be formed in boron-based (Vycor) glasses after chemical etching of sodium (and boron) matrices. Recent measurements of the $o$-Ps lifetime in Vycor glasses [25] vs. temperature showed some persistent hysteresis: lifetimes change after cooling cycles and remain such until baking of the sample is applied. Measurements without the use of positron beams hardly explain this problem.

Brusa and collaborators [26, 27] exploited a similar question using energy-controlled positron beam and monitoring all three parameters (S, W, V) of DB. Material under study were thin layers $(310 \mathrm{~nm})$ of porous, low- $\varepsilon \mathrm{SiOCH}$, deposited on Si by plasma reactions from trimethylsilane. Layers were then capped by a 45-nm thick layer formed in a separate $\mathrm{N}_{2}$ discharge.

Positron beam measurements aimed to explain aging properties of such layers. In Fig. 1, we present the ratio $R$ between the low-energy wing parameter $\mathrm{V}$, corresponding to gamma energies between $410 \mathrm{keV} \leq E_{\gamma} \leq 500 \mathrm{keV}$, and the central part parameter $\mathrm{S}, E_{\gamma}=511 \pm 0.85 \mathrm{keV}$. This ratio reflects the annihilation into three gamma quanta, because of the $o$-Ps formation. Positron implantation energy was between $80 \mathrm{eV}$ and $26 \mathrm{keV}$, what in this sandwich material corresponds to the depth between $3 \mathrm{~nm}$ and $5 \mu \mathrm{m}$. The deconvolution of the annihilation parameters vs. the positron implantation depth (and diffusion) was done with VEPFIT numerical package.

At the depth between capping and the silicon substrate, high values of the $R$ parameter (up to $R=7$ in the center of the layer) are visible, indicating porosity of the $\mathrm{SiOCH}$ layer. Assuming the spherical shape of pores, their size of about 1.3-1.4 $\mathrm{nm}$ was deduced. Annealing the samples at $900^{\circ} \mathrm{C}$ causes pores to coalesce, bringing $R$ parameter to the value of about 2 . A change in $R$ parameters is also seen between 600 and $700^{\circ} \mathrm{C}$, indicating probably a chemical change in the lining of nanocavities (no such a change is seen in S parameter).

Storing samples in air for one month causes a similar effect as the high-temperature annealing - pores seem to disappear [27], but the reason is different: pores get filled with water vapor. The original value of $R$ in the layer re-emerges after annealing at $400^{\circ} \mathrm{C}$. Aging is much faster $(48 \mathrm{~h})$ in $\mathrm{H}_{2} \mathrm{O}$ atmosphere and slower in $\mathrm{H}_{2}$ or $\mathrm{O}_{2}$ atmospheres.

A layer-by-layer comparison of $\mathrm{S}$ and the $\mathrm{W}$ ('wing' $1.6 \mathrm{keV} \leq\left|E_{\gamma}-511 \mathrm{keV}\right| \leq 4.25 \mathrm{keV}$ ) parameters allows to deduce the stoichiometry of the 
a)

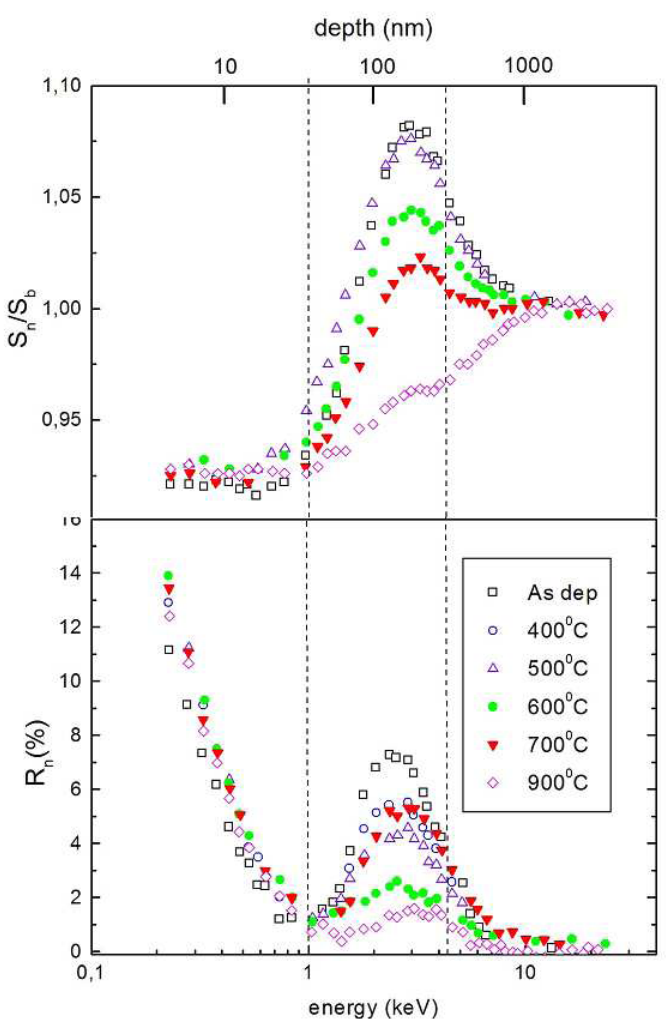

b)

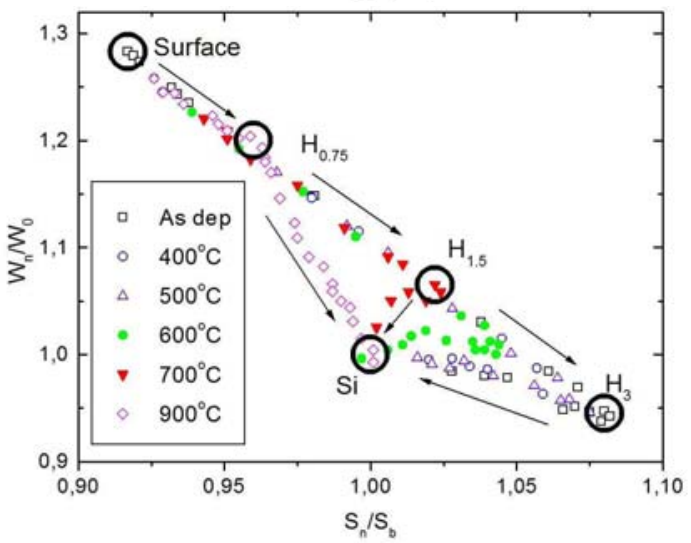

Fig. 1. Positron-beam measurements on $\mathrm{SiOCH}$ capped films (Trento laboratory, adapted from [26, 27]). (a) Fraction of $3 \gamma$ annihilation (qualitatively, formation of long-lived, $o$-Ps) for samples annealed at different temperatures (lower panel) and the normalized S parameter (upper panel). (b) Correlation plot between S (low electron momentum) and $\mathrm{W}$ (high electron momentum) parameters, indicating different types of defects and chemical structures at different depths.

$\mathrm{SiOCH}$ layer, see Fig. 1b. The $(\mathrm{S}, \mathrm{W})$ point with $(1.0,1.0)$ values corresponds to pure Si (spectra were normalized to these values), the left upper corner - to pure $\mathrm{SiO}_{2}$ while points on the slopes of the 'triangle' - to different stoichiometries. The right lower point corresponds, as we deduce from additional Raman spectra [26]), to $\mathrm{SiO}_{1.5} \mathrm{C}_{1.2} \mathrm{H}_{3}$, in the middle of the porous layer.

\section{Case study II - hydrogen and helium in silicon}

Helium implantation in silicon over a certain flux $\left(2 \times 10^{16} \mathrm{~cm}^{2}\right)$ causes formation of nanobubbles.
Brusa et al. [28] via DB measurements with the variable-energy positron beam showed that a lower dose of $\mathrm{He}^{+}\left(0.5 \times 10^{16} \mathrm{~cm}^{2}\right)$ also leads, in the first moment, to the formation of vacancies in Si. However, the defects do not grow to vacancy clusters, so they disappear after an appropriate annealing treatment. DB data [28], supported by the theory [7], allowed to identify mono-, bi-, and trivacancies and vacancy clusters in irradiated $\mathrm{Si}$.

The helium and hydrogen coimplantation leads to blistering in $\mathrm{Si}$; this effect cannot be obtained by $\mathrm{He}^{+}$ or $\mathrm{H}^{+}$implantation alone. Samples with the implantation dose of $10^{16} \mathrm{~cm}^{-2}$ of $\mathrm{He}^{+}$(at $30 \mathrm{keV}$ of energy) and the same dose of $\mathrm{H}^{+}$(and $24 \mathrm{keV}$ of energy) were studied with three combined positron techniques, in joint Trento and München measurements [29]. Electron transmission microscopy shows the presence of nanocavities at the mean depth of $290 \mathrm{~nm}$. DB measurements themselves did not reveal clearly the presence of these nanocavities - the $S$ curve shows only a weak maximum, see Fig. 2a. The DB $S$ curve has been deconvoluted using additional information from measurements by a coincidence method, in which the ambient gamma background at $E_{\gamma} \geq 511 \mathrm{keV}$ is reduced. This method allows to extract better signal from high-momentum (i.e., core) electrons, and in this way, detect the chemical species around defects, see [8]. Such curves are shown in Fig. 2: at different implantation depths, different chemical species are present. Buried cavities in Si are decorated by oxygen atoms [29]. Such conclusion is supported by depth-resolved lifetime measurements from München pulsed beam (Fig. 2c).

\section{Case study III - materials for fusion reactors}

A thermonuclear reaction would solve energy problems for centuries. Currently, a 13-bln euro, common EU, United States, Brazil, India, Russia and Korea project, ITER in Cadarache was started, aiming to obtain a net energy production. The difficulty stays not in the reaction itself, but in constructing the container for $150 \mathrm{mln} \mathrm{K}$ plasma.

Previous generation reactors (such as JET) were lined with carbon. Carbon sputtering (and formation of hydrocarbons [30]) was a part of the thermonuclear reaction dynamics, determining, for example, the edge plasma temperature and density and also a limitation of the operational efficiency. The ITER reactor is lined with $\mathrm{W}$ in the divertor and with $\mathrm{Be}$ in the rest of the chamber. High heat fluxes are expected in the divertor, apart from neutron, $\mathrm{He}$, $\mathrm{H}$ atoms, and ions bombardments. Theory [31] indicates that $\mathrm{He}$ and $\mathrm{H}$ coimplantation in $\mathrm{W}$ can cause similar blistering as in Si. However, tests simulating the fusion environment indicated that exposure of $\mathrm{W}$ to deuterium atmosphere but seeded with He could result in suppression of blisters, see, for example, $[32,33]$. Ogorodnikova and Sugiyama [34] showed that tungsten exposed to deuterium plasma is subject to bigger damage than Eurofer that is proposed as a structure material for next-generation reactors. Recently, Ogorodnikova and Gann [35] showed that 


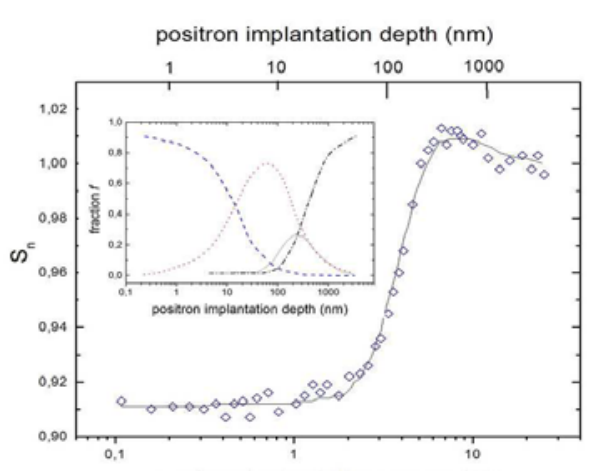

a)

positron implantation energy $(\mathrm{eV})$

b)
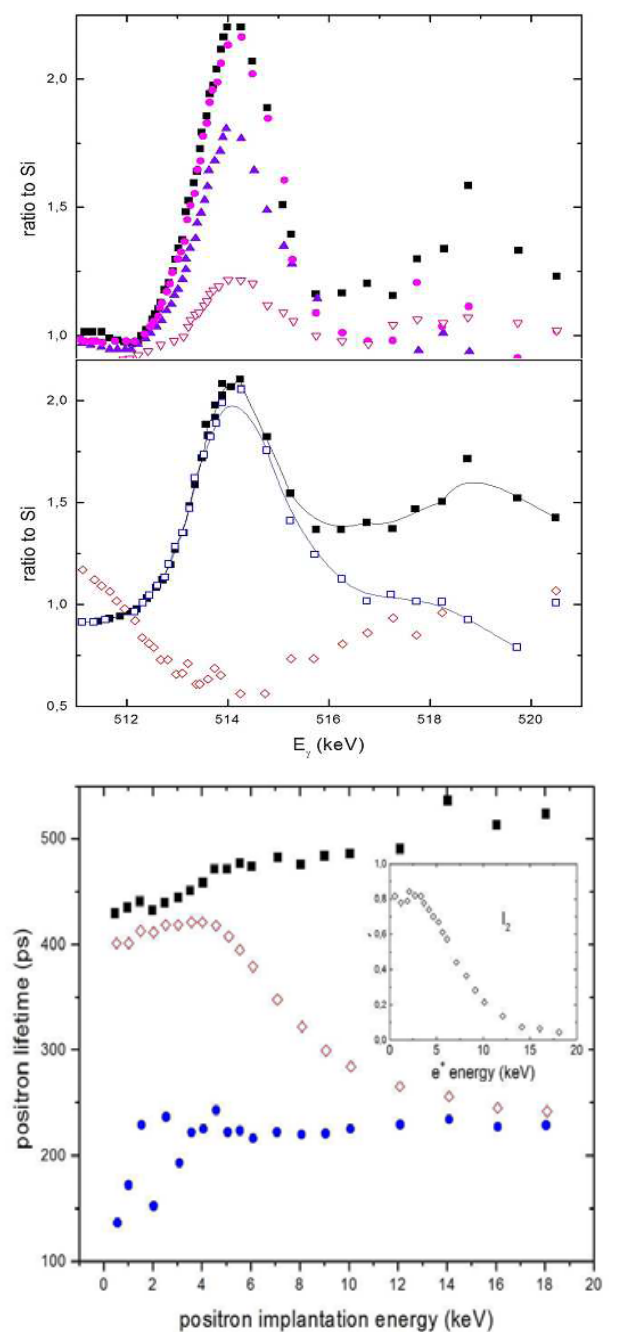

Fig. 2. Blistering in Si studied by three positron-beam techniques. (a) Measurement and deconvolution (inset) of S parameter (Trento laboratory). (b) Doppler-broadening with reduction of the high-momentum background by coincidence technique: upper panel - ratio of S parameter to that in $\mathrm{Si}$ at four positron implantation energies: full (black) squares $E=0.15 \mathrm{keV}$, full (magenta) circles $E=$ $1 \mathrm{keV}$, full (violet) triangles $E=3 \mathrm{keV}$, inverted (pink) triangles $E=6.5 \mathrm{keV}$; lower panel - characteristic ratio curves extracted via the diffusion equation from measurements: positrons annihilating at the surface, full squares; at buried surfaces, open (blue) squares; in the clean nanocavities, open (red) diamonds. (c) Positron lifetimes - open (red) diamonds, mean lifetime; full (blue) circles, $\tau_{1}$; full (black) squares, $\tau_{2}$; inset, lifetime intensity $I_{2}$ vs. positron implantation energy (München measurements). Adapted from [29]. deuterium trapping in $\mathrm{W}$ is related to radiation damage. Positron annihilation S-W curves from Orleans laboratory [36] indicated that apart from vacancies, some small vacancy clusters are formed in tungsten even at low-damage level.

In present work, samples of polycrystalline $\mathrm{W}$ ITER-grade were studied with the pulsed low-energy positron beam system (PLEPS) [37] at the high-intensity positron beam facility NEPOMUC at the MLZ [38] in Garching (München). All specimens were recrystallized prior to any irradiation treatment in order to reduce the density of initial intrinsic defects. Three types of samples were studied: undamaged samples, samples irradiated with $20 \mathrm{MeV}$ tungsten $\mathrm{W}^{6+}$ ions (at two different fluxes, $1.6 \times$ $10^{12} / \mathrm{cm}^{2}$ and $1.6 \times 10^{14} / \mathrm{cm}^{2}$, at room temperature), and irradiated with $3.5 \mathrm{MeV}$ electrons $\left(4.3 \times 10^{18}\right)$ $\mathrm{cm}^{2}$ and $1.3 \times 10^{19} / \mathrm{cm}^{2}$, at room temperature). Two positron implantation energies were used, 16 and $18 \mathrm{keV}$, corresponding to the mean depth of 170 and $200 \mathrm{~nm}$. Positron profiles extend down to some $400 \mathrm{~nm}$. Preliminary results of lifetime spectra are shown in Fig. 3.

The W-ion implantation significantly changes lifetime spectra, introducing a long-time component (see Fig. 3a). In contrast, no much significant damage is seen in samples implanted by electrons. Deconvolution of spectra with WINFIT numerical

a)
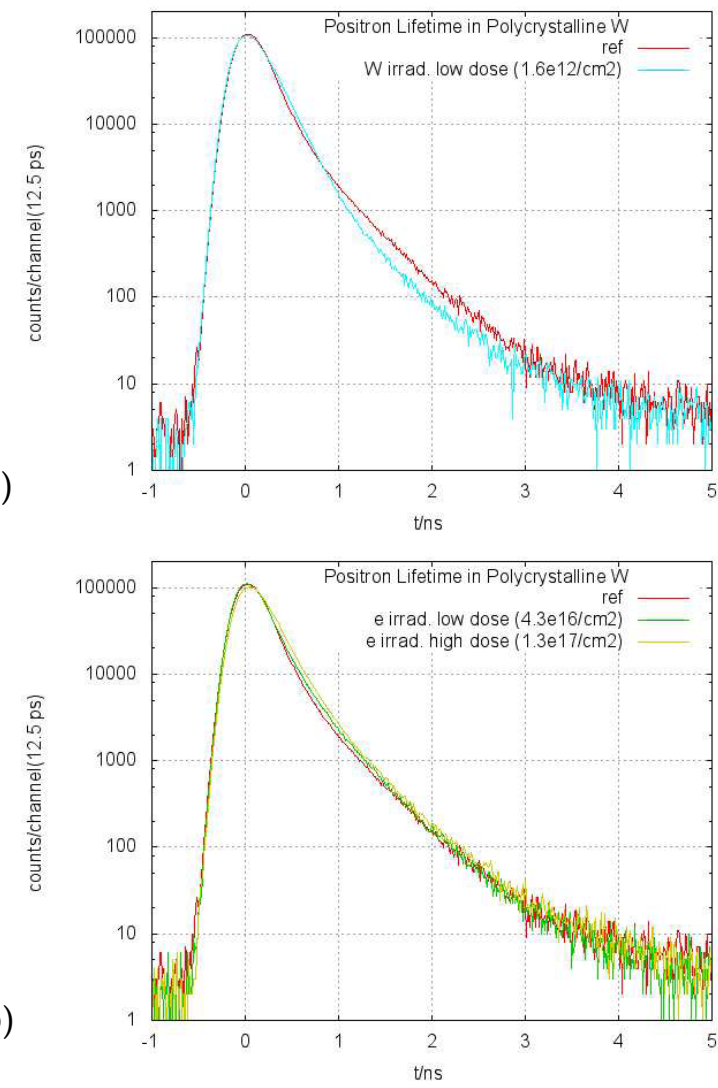

Fig. 3. Positron lifetime spectra of ITER-grade tungsten. (a) Polycrystalline $\mathrm{W}$ - reference sample (red, i.e., upper curve), $\mathrm{W}^{+6}$ irradiated (lower, cyan). (b) Electron implanted samples: high dose (yellow, uppermost), low dose (green, intermediate), and the reference samples (lowest curve, red). Preliminary data from München pulsed low-electron positron beam system (PLEPS). 
Table 1. Mean positron lifetimes as studied by München beam in reference and irradiated W samples

\begin{tabular}{lcccc}
\hline Reference sample & W low & W high & e low & e high \\
\hline 170 & 182 & 245 & 170 & 200 \\
\hline
\end{tabular}

package, with 240-ps apparatus time resolution, gives in reference samples a dominating $(80 \%$ intensity) short (118 ps) lifetime, with some ( $370 \mathrm{ps})$ intermediate lifetime component, that could indicate annihilation on grain boundaries.

Note that bulk measurements (Trento lifetime apparatus, 180 ps resolution) in annealed monocrystal $\mathrm{W}$ gave 103 and 240 ps (9\%) lifetime components [14], compatible with present data. In high-dose W ion-implanted samples, the positron signal goes into saturation: no short lifetime is visible, what indicates a high concentration of positron-trapping defects (vacancies, oligovacancies, and clusters of vacancies, probably). The annihilation spectra are dominated (with $80 \%$ intensity) by a 220 -ps component. The rest of positrons are trapped by large defects (lifetime of $\sim 500 \mathrm{ps}$ ). This would be compatible with Orsay data [36] on positron-annihilation DB of self-ion-irradiated tungsten and saturation in the $\mathrm{D}$ decoration of radiation-induced defects at irradiation dose of around $1.6 \times 10^{14} \mathrm{~W} / \mathrm{cm}^{2}$ as it was reported also in [35]. Results in samples irradiated with W ions at low dose are not so clear. A dominant lifetime (with $83 \%$ intensity) is $187 \mathrm{ps}$, somewhat lower than that in samples irradiated at low dose.

The results for samples irradiated with electrons are far from being conclusive: little change in lifetimes is seen, see Fig. 3b. A short component of about $130-140$ ps (about 60\% intensity) can be deconvoluted but longer components are mixed. Total trapping of positron into defects can be envisaged in the high-dose electron-implanted samples but the extraction of other lifetimes would require much better statistics (and measurement times). Positron mean lifetimes in studied samples are given in Table 1.

\section{Toward a European Network}

An increasing level of technological complexity in the economical competition requires more and more sophisticated diagnostic methods in material science. This is not the cost of work power but technological progress, which makes new products competitive: unique properties of materials resulting from their composition, manufacturing, and post-processing that define technological applications. New diagnostic methods are urgently needed, especially for defectoscopy, damage, and aging.

Positron annihilation techniques were developed in United States, in 60s of past century [39]. In the EU framework, a worldwide unique scanning positron microscope has been constructed within the BRITE-Euram Programme jointly by München and Trento laboratories [40, 41] and successfully applied to problems of fatigue and fracture in metals [42], but the technological impact of this project was limited, mainly because of the low posi- tron intensities available with conventional laboratory positron sources, and therefore, it is currently set up at the NEPOMUC facility. Japanese positron beam in Tsukuba continues to challenge important questions, mainly in the field of semiconductors [43]. The beam constructed within a national programme at the Australian National University in Canberra is dedicated mainly to atomic physics [44]. Currently operating positron beams, among others, in Helsinki [45], Halle [46], London [47], Delft [48], and Orleans [49] rarely go beyond national contexts and specialized applications, with the exception of the NEPOMUC facility, where scientists of European countries have access within the EU great facilities NI3 programme.

Huge EU funds allocated to research and development (54 bln euro in 7th Framework via XIIth Directorate only) make possible setting up a tight network of European positron laboratories for material studies with positrons, with the main aim to bundle and coordinate the different competences scattered among the different laboratories, so that more comprehensive positron investigations become possible.

Factors for this opportunity are:

- subjects that found a methodological barrier when using traditional investigations [23],

- new challenges for material in manufacturing consumables, transportation, energetics, environmental protection, and healthy societies,

- global, expanding outside EU search for positron answers [31],

- growing scientific infrastructures in 'emerging' countries,

- vast EU experience in projecting positron beams [8, 14-18, 40, 46, 48, 49].

\section{References}

1. Dupasquier, A., Mills Jr, A. P., \& Brusa, R. (Eds.). (2010). Physics with many positrons. 174th Proceedings of the International School of Physics "Enrico Fermi". Amsterdam: IOS Press.

2. Brusa, R. S., Macchi, C., Mariazzi, S., Karwasz, G. P., Scarel, G., \& Fanciulli, M. (2007). Innovative dielectrics for semiconductor technology. Radiat. Phys. Chem., 76(2), 189-194. DOI: 10.1016/j.radphyschem.2006.03.033.

3. Karwasz, G. P., Zecca, A., Brusa, R. S., \& Pliszka, D. (2004). Application of positron annihilation techniques for semiconductor studies. J. Alloy. Compd., 382(1/2), 244-251. DOI: 10.1016/j.jallcom.2004.05.037.

4. Dupasquier, A., Kögel, G., \& Somoza, A. (2004). Studies of light alloys by positron annihilation techniques. Acta Mater., 52, 4707. DOI: 10.1016/j. actamat.2004.07.004.

5. Goworek, T., Zaleski, R., \& Wawryszczuk, J. (2004). Observation of intramolecular defects in n-alkanes $\mathrm{C}_{25} \mathrm{H}_{52}-\mathrm{C}_{29} \mathrm{H}_{60}$ by the positron annihilation method. 
Chem. Phys. Lett., 394, 90-92. DOI: 10.1016/j. cplett.2004.06.116

6. Śniegocka, M., Jasińska, B., Goworek, T., \& Zaleski, R. (2006). Temperature dependence of o-Ps lifetime in some porous media. Deviations from ETE model. Chem. Phys. Lett., 430, 351-354. DOI: 10.1016/j. cplett.2006.09.001.

7. Hakala, M., Puska, M. J., \& Nieminen, R. M. (1998). Momentum distributions of electron-positron pairs annihilating at vacancy clusters in Si. Phys. Rev. B, 57, 7621. DOI: 10.1103/PhysRevB.57.7621.

8. Brusa, R. S., Deng, W., Karwasz, G. P., \& Zecca, A. (2002). Doppler-broadening measurements of positron annihilation with high-momentum electrons in pure metals. Nucl. Instrum. Methods Phys. Res. Sect. B-Beam Interact. Mater. Atoms, 194, 519-531. DOI: 10.1016/S0168-583X(02)00953-9.

9. Karbowski, A., Fidelus, J., \& Karwasz, G. (2011). Testing an Ortec Lifetime System. Mater. Sci. Forum, 666, 155-159. DOI: 10.4028/www.scientific.net/ MSF.666.155.

10. Karbowski, A., Fisz, J. J., Karwasz, G. P., Kansy, J., \& Brusa, R. S. (2008). Genetic algorithms for positron lifetime data. Acta Phys. Pol. A, 113, 1365-1372.

11. Brusa, R., Deng, W., Karwasz, G. P., Zecca, A., \& Pliszka, D. (2001). Positron annihilation study of vacancy-like defects related to oxygen precipitates in Czochralski-type Si. Appl. Phys. Lett., 79, 1492. DOI: 10.1063/1.1401782.

12. Saarinen, K., Nissilä, J., Kauppinen, H., Hakala, M., Puska, M. J., Hautojärvi, P., \& Corbel, C. (1999). Identification of vacancy-impurity complexes in highly n-type Si. Phys. Rev. Lett., 82, 1883-1886. DOI: 10.1103/PhysRevLett.82.1883.

13. Coleman, P. G. (Ed.). (2000), Positron beams and their applications. Singapore: World Scientific.

14. Brusa, R. S., Karwasz, G. P., Bettonte, M., \& Zecca, A. (1997). A high performance electrostatic positron beam. Appl. Surf. Sci., 116, 59-62. DOI: 10.1016/ S0169-4332(96)01028-8.

15. Zecca, A., Bettonte, M., Paridaens, J., Karwasz, G. P., \& Brusa, R. S. (1998). A new electrostatic positron beam for surface studies. Meas. Sci. Technol., 9, 409-416. DOI: 10.1088/0957-0233/9/3/014.

16. Zecca, A., Brusa, R. S., Duarte-Naia, M., Karwasz, G. P., Paridaens, J., Piazza, A., Kögel, G., Sperr, P., Britton, D. T., Uhlmann, K., Willutzki, P., \& Triftshauser, W. (1995) A pulsed positron microbeam. Europhys. Lett., 29, 617-622. DOI: 10.1209/02955075/29/8/005.

17. Hamada, E., Oshima, N., Suzuki, T., Kobayashi, H., Kondo, K., Kanazawa, I., \& Ito, Y. (2000). New system for a pulsed slow-positron beam using a radioisotope. Radiat. Phys. Chem., 58, 771-775. DOI: 10.1016/S0969-806X(00)00257-7.

18. Hugenschmidt, C., Piochacz, C., Reiner, M., \& Schrekkenbach, K. (2012). The NEPOMUC upgrade and advanced positron beam experiments. New J. Phys., 14, 055027. DOI: 10.1088/1367-2630/14/5/055027.

19. Oshima, N., Suzuki, R., Ohdaira, R., Kinomura, A., Narumi, T., Uedono, A., \& Fujinami, M. (2008). Brightness enhancement method for a high-intensity positron beam produced by an electron accelerator. $J$. Appl. Phys., 103, 094916. DOI: 10.1063/1.2919783.

20. Brusa, R. S., Macchi, C., Mariazzi, S., Karwasz, G. P., Laidani, N., Bartali, R., \& Anderle, M. (2005). Amorphous carbon film growth on $\mathrm{Si}$ : Correlation between stress and generation of defects into the substrate. Appl. Phys. Lett., 86, 221906. DOI: 10.1063/1.1940738.
21. Ferragut, R., Calloni, A., Dupasquier, A., Consolati, G., Quasso, F., Giammarchi, M. G., Trezzi, D., Egger, W., Ravelli, L., Petkov, M. P., Jones, S. M., Wang, B., Yaghi, O. M., Jasińska, B., Chiodini, N., \& Paleari, A. (2010). Positronium formation in porous materials for antihydrogen production. J. Phys. Conf. Ser., 225, 012007. DOI: 10.1088/1742-6596/225/1/012007.

22. Consolati, G. (2002). Positronium trapping in small voids: Influence of their shape on positron annihilation results. J. Chem. Phys., 117, 7279. DOI: 10.1063/1.1507578.

23. Jasińska, B., \& Dawidowicz, A. L. (2003). Pore size determination in Vycor glass. Radiat. Phys. Chem., 68(3/4), 531-534. DOI: 10.1016/S0969806X(03)00224-X.

24. Jasińska, B., Dawidowicz, A. L., Goworek, T., \& Wawryszczuk, J. (2003). Pore size determination by positron annihilation lifetime spectroscopy. Opt. Appl., 33(1), 7-12.

25. Gorgol, M., Jasińska, B., \& Reisfeld, R. (2015). PALS investigations of matrix Vycor glass and doped by molecules of luminescent dye and silver nanoparticles. Discrepancies from the ETE model. Nukleonika, 60(4), 717-720.

26. Macchi, C., Mariotto, G., Karwasz, G. P., Zecca, A., Bettonte, M., \& Brusa, R. S. (2004). Depth profiled porosity and micro-structure evolution studied by Positron Annihilation and Raman spectroscopy in SiOCH low-к films. Mater. Sci. Semicond. Proc., 7, 289-294. DOI: 10.1016/j.mssp.2004.09.093.

27. Brusa, R. S., Spagolla, M., Karwasz, G. P., Zecca, A., Ottaviani, G., Corni, F., \& Carollo, E. (2004). Porosity in low dielectric constant SiOCH films depth profiled by positron annihilation spectroscopy. J. Appl. Phys., 95, 2348-2354. DOI: 10.1063/1.1644925.

28. Brusa, R. S., Karwasz, G. P., Tiengo, N., Zecca, A., Corni, F., Tonini, R., \& Ottaviani, G. (2000). Formation of vacancy clusters and cavities in He-implanted silicon studied by slow-positron annihilation spectroscopy. Phys. Rev. B, 61, 10154-10166. DOI: 10.1103/ PhysRevB.61.10154.

29. Brusa, R. S., Macchi, C., Mariazzi, S., Karwasz, G. P., Egger, W., Sperr, P., \& Kögel, G. (2006). Decoration of buried surfaces in Si detected by positron annihilation spectroscopy. Appl. Phys. Lett., 88, 011920. DOI: 10.1063/1.2162691.

30. Song, M. -Y., Yoon, J. -S., Cho, H., Itikawa, Y., Karwasz, G. P., Kokoouline, V., Nakamura, Y., \& Tennyson, J. (2015). Cross sections for electron collisions with methane. J. Phys. Chem. Ref. Data, 44, 023101. DOI: $10.1063 / 1.4918630$.

31. Yu-Wei, You, Dongdong, Li, Xiang-Shan, Kong, Xuebang, Wu, Liu, C. S., Fang, Q. F., Pan, B. C., Chen, J. L., \& Luo, G. -N. (2014). Clustering of $\mathrm{H}$ and He, and their effects on vacancy evolution in tungsten in a fusion environment. Nucl. Fusion, 54, 103007. DOI: 10.1088/0029-5515/54/10/103007.

32. Ogorodnikova, O. V., Schwarz-Selinger, T., Sugiyama, K., \& Alimov, V. Kh. (2011). Deuterium retention in tungsten exposed to low-energy pure and helium-seeded deuterium plasmas. J. Appl. Phys., 109, 013309. DOI: 10.1063/1.3505754.

33. Tyburska-Püschel, B., Alimov, V. Kh, 't Hoen, M. H. J., Zgardzinska, B., Dorner, J., \& Hatano, Y. (2013). Deuterium retention in tungsten damaged with $\mathrm{MeV}$ -range $\mathrm{W}$ ions at various temperatures and then exposed to $\mathrm{D}_{2}$ gas. In 14th International Conference on Plasma-Facing Materials and Components for Fusion Applications, May 13-17, 2013. Forschungszentrum Juelich, Germany. http://www.fz-juelich.de/confer- 
ences/PFMC-14/EN/_SharedDocs/Downloads/EN/ pfmc14 book_of abstracts.html?nn=1264182.

34. Ogorodnikovā, O. V., \& Sugiyama, K. (2013). Effect of radiation-induced damage on deuterium retention in tungsten, tungsten coatings and Eurofer. $J$. Nucl. Mater., 442, 518-527. DOI: 10.1016/j.jnucmat.2013.07.024

35. Ogorodnikova, O. V., \& Gann, V. (2015). Simulation of neutron-induced damage in tungsten by irradiation with energetic self-ions. J. Nucl. Mater., 460, 60-71. DOI: 10.1016/j.jnucmat.2015.02.004.

36. Ogorodnikova, O. V., Sugiyama, K., Barthe, M. -F., Sibid, M., Ciupiński, Ł., \& Płociński, T. (2013). Saturation of deuterium trapping at radiation-induced damage in self-ion irradiated tungsten. In 16th International Conference on Fusion Reactor Materials (ICFRM-16), Beijing, China. http://edoc.mpg. $\mathrm{de} / 634511$.

37. Egger, W. (2010). Pulsed low-energy positron beams in materials sciences. In R. S. Brusa, A. Dupasquier, \& A. P. Mills Jr. (Eds.), Physics with many positrons (pp. 419-449). Amsterdam: North-Holland Publ. Co.

38. Hugenschmidt, C. (2010). Positron sources and positron beams. In R. S. Brusa, A. Dupasquier, \& A. P. Mills Jr. (Eds.), Physics with many positrons (pp. 399-417). Amsterdam: North-Holland Publ. Co.

39. Brandt, W., Berko, S., \& Walker, W. W. (1960). Positronium decay in molecular substances. Phys. Rev., 120, 1289-1295.

40. Uhlmann, K., Triftshäuser, W., Kögel, G., Sperr, P., Britton, D. T., Zecca, A., Brusa, R. S., \& Karwasz, G. P. (1995). A concept of a scanning positron microscope. Fresenius J. Anal. Chem., 353, 594-597. DOI: 10.1007/BF00321331.

41. Zecca, A., \& Karwasz, G. (2001). Positrons go into detail. Phys. World, 11, 21.

42. Kögel, G., Egger, W., Rödling, S., \& Gudladt, H. J. (2004). Investigation of fatigue cracks in an Al-based alloy by means of pulsed positron (micro)beams.
Mater. Sci. Forum, 445/446,126-128. DOI: 10.4028/ www.scientific.net/MSF.445-446.126.

43. Uedono, A., Kurihara, K., Yoshihara, N., Nagao, S., \& Ishibashi, S. (2015). Vacancies in $\operatorname{In}_{x} \mathrm{Ga}_{1-\mathrm{x}} \mathrm{N} / \mathrm{GaN}$ multiple quantum wells fabricated on $m$-plane $\mathrm{GaN}$ probed by a monoenergetic positron beam. Appl. Phys. Express, 8, 051002. DOI: 10.7567/APEX.8.051002.

44. Makochekanwa, C., Machacek, J. R., Jones, A. C. L., Caradonna, P., Slaughter, D. S., McEachran, R. P., Sullivan, J. P., Buckman, S. J., Bellm, S. M., Lohmann, B., Fursa, D. V., Bray, I., Mueller, D. W., Stauffer, A. D., \& Hoshino, M. (2011). Low-energy positron interactions with krypton. Phys. Rev. A, 83, 032721. DOI: 10.1103/PhysRevA.83.032721.

45. Pelli, A., Laakso, A., Rytsölä, K., \& Saarinen, K. (2006). The design of the main accelerator for a pulsed positron beam. Appl. Surf. Sci., 252, 3143-3147. DOI: 10.1016/j.apsusc.2005.08.054.

46. Wagner, A., Anwand, W., Butterling, M., Cowan, T. E., Fiedler, F., Fritz, F., Kempe, M., \& Krause-Rehberg, R. (2015). Positron-annihilation lifetime spectroscopy using electron Bremsstrahlung. $J$. Phys. Conf. Ser., 618, 012042. DOI: 10.1088/17426596/618/1/012042.

47. Köver, A., Williams, A. I., Murtag, D. J., Fayer, S. E., \& Laricchia, G. (2014). An electrostatic brightness-enhanced timed positron beam for atomic collision experiments. Meas. Sci. Technol., 25, 075013. DOI: 10.1088/0957-0233/25/7/075013.

48. Schut, H., Van Veen, A., de Roode, J., \& Labohm, F. (2004). Long term performance of the reactor based positron beam POSH. Mater. Sci. Forum, 445/446, 507-509.

49. Desgardin, P., Liszkay, L., Barthe, M. F., Henry, L., Briaud, J., Saillard, M., Lepolotec, L., Corbel, C., Blondiaux, G., Colder, A., Marie, P., \& Levalois, M. (2001). Slow positron beam facility in Orleans. Mater. Sci. Forum, 363, 523-525. 